\title{
OS DIREITOS HUMANOS E O ACESSO À JUSTIÇA: Uma Análise Histórico-Conceitual de um Direito Fundamental para a Convivência Humana Pacífica
}

\author{
http://dx.doi.org/10.21527/2176-6622.2018.50.75-86
}

Recebido em: 7/6/2018

Aceito em: 25/9/2018

\section{Gilmar Antonio Bedin}

Doutor em Direito do Estado. Professor permanente do curso de Mestrado em Desenvolvimento da Unijuí e professor-colaborador da URI. gilmarb@unijui.edu.br

\section{Elenise Felzke Schonardie}

Doutora em Ciências Sociais pela Universidade do Vale do Rio dos Sinos - Unisinos. Mestre em Direito pela Universidade de Santa Cruz do Sul - Unisc. Professora do Programa de Pós-Graduação Stricto Sensu em Direito - Curso de Mestrado em Direitos Humanos da Universidade Regional do Noroeste do Estado do Rio Grande do Sul - Unijuí. Membro do Grupo de Pesquisa Direitos Humanos, Globalização e Equidade e professora do curso de Graduação em Direito da Unijuí. Advogada. elenise.schonardie@unijui.edu.br

\section{RESUMO}

O presente artigo busca contextualizar a temática do direito de acesso à justiça sob a ótica dos direitos humanos. A análise inicia-se pela trajetória histórica de evolução dos direitos humanos nas sociedades ocidentais e sua apresentação em gerações. Na sequência, demonstra-se a significativa expansão do direito de acesso à justiça no mundo moderno, sua importância e a preocupação no âmbito legislativo nacional e internacional. Por fim, conclui que o direito de acesso à justiça é uma forma de mediação democrática dos conflitos e constitui-se num instrumento de pacificação social e de educação para a convivência humana pacífica e voltada ao fortalecimento do Estado de Direito e ao respeito à dignidade humana.

Palavras-chave: Direitos humanos. Gerações de direitos. Acesso à justiça. Respeito à dignidade humana.

\section{HUMAN RIGHTS AND ACCESS TO JUSTICE: A HISTORICAL-CONCEPTUAL ANALYSIS OF A FUNDAMENTAL RIGHT FOR THE PEACEFUL HUMAN COEXISTENCE}

\section{ABSTRACT}

The present article searches to contextualize the thematic of the right of access to justice under the optical of the human rights. The analysis starts with the historical trajectory of the evolution of human rights in western societies and their presentation in generations. In the sequence, it is demonstrated the significant expansion of the right of access to justice in the modern world, its importance and concern in the national and international legislative scope. Lastly, it concludes that the right of access to justice is a form of democratic mediation of conflicts and constitutes an instrument of social pacification and of education for the peaceful human coexistence and aimed at strengthening the Rule of Law and to respect to human dignity.

Keywords: Human rights. Generations of rights. Access to justice. Respect to human dignity.

\section{SUMÁRIO}

1 Considerações iniciais. 2 As gerações de Direitos Humanos. 30 Direito ao acesso à justiça. 4 A proteção nacional e internacional do Direito de acesso à justiça. 5 Considerações finais. 6 Referências. 


\section{CONSIDERAÇÕES INICIAIS}

O direito de acesso à justiça tem chamado atenção nesses tempos em que as sociedades ocidentais dos países desenvolvidos e dos países em desenvolvimento, como o Brasil, têm sofrido com a expansão do capitalismo avançado que impõem, às nações, uma agenda significativa de redução da proteção dos direitos humanos, em especial dos direitos econômicos e sociais. Nesse quadro, a luta pela manutenção dos direitos humanos, arduamente conquistados ao longo da modernidade, tem se mostrado relevante e um desafio permanente.

Os grandes contrastes sociais oriundos de um sistema econômico altamente complexo de expulsão ${ }^{1}$ de indivíduos, deve encontrar seu limite ou resistência na luta pela dignidade humana e suas consequências. Assim, descobrir espaços para a reivindicação de direitos, por meio do acesso à justiça, torna-se essencial em sociedades atuais integradas em um mundo em grande transformação.

Destarte, propõe-se o enfrentamento da temática do direito de acesso à justiça sob a ótica da busca pela eficácia dos direitos humanos. Nesse sentido, o presente trabalho, por meio da pesquisa teórica e da utilização do método de abordagem hipotético-dedutiva, principia a apresentação da trajetória de evolução histórica dos direitos humanos, o que faz por intermédio das chamadas gerações clássicas dos direitos humanos, prolongando-se até o reconhecimento de direitos de última geração.

Na sequência, o direito ao acesso à justiça é apresentado por meio da análise de seus principais expoentes, os juristas Mauro Cappelletti e Bryant Garth, pelos quais acompanhamos a significativa expansão deste direito ao longo da modernidade, ou seja, do seu reconhecimento inicial como direito civil para um direito que vai além da garantia de acesso ao Poder Judiciário pelos indivíduos necessitados em razão de sua insuficiência econômica e exclusão social.

Em um terceiro momento, o texto contempla, a proteção nacional e internacional do direito de acesso à justiça. Em relação ao âmbito nacional, destaca-se a importância da previsão constitucional no reconhecimento do direito de acesso à justiça como direito humano e as formas de sua materialização. No que se refere ao âmbito internacional, chama a atenção para a importância dos principais documentos legislativos, seja no reconhecimento ou no apoio ao reconhecimento do direito do acesso à justiça pelas nações que integram a sociedade internacional, visando a sua compreensão enquanto direito humano essencial à afirmação da dignidade humana.

\section{AS GERAÇÕES DE DIREITOS HUMANOS}

A trajetória histórica da construção dos direitos humanos possui uma longa caminhada. Seu reconhecimento e proteção tem como pressuposto necessário a paz entre os Estados e, hodiernamente, esses direitos encontram-se na base das Constituições democráticas modernas. Não obstante, esta caminhada iniciou-se com as declarações de direitos de 1776 (Declaração da Virgínia) e de 1789 (Declaração dos Direitos do Homem e do Cidadão), passou pela Declaração Universal dos Direitos do Homem (1948) e alcança a Declaração e o Plano de Ação de Viena (1993), apenas para citar algumas das declarações de direitos mais importantes.

Nesse sentido, pode-se afirmar que, desde as primeiras declarações, a luta pelo reconhecimento e pelo respeito aos direitos humanos tem progredido, apesar de todas as dificuldades, de forma extraordinária, tendo sido enriquecida por várias gerações de direitos sucessivas. ${ }^{2}$ Estas gerações ${ }^{3}$ são as seguintes: 1ạ) Direitos

\footnotetext{
${ }^{1}$ Nesse sentido ver a obra Expulsões: brutalidade e complexidade na economia global, de Saskia Sassen (2016).

${ }^{2}$ Isto não significa, contudo, que se desconhece a dimensão de interdependência e de indivisibilidade das várias gerações de direitos. A classificação adotada é apenas uma forma metodológica de apresentar os vários grupos de direitos. Para melhor entender a questão da interdependência e indivisibilidade dos direitos humanos, indica-se a obra de Antônio Augusto Cançado Trindade (2003).

${ }^{3}$ A ideia de generatividade geracional dos direitos humanos, também não é totalmente correta, pois os direitos são de todas as gerações. [...] "não se trata apenas de direitos com um suporte colectivo - os direitos dos povos, o direito da humanidade. Neste sentido se fala de solidaritu rights, de direitos de solidariedade, sendo certo que a solidariedade já era uma dimensão indimensionável dos direitos econômicos, sociais e culturais. Precisamente por isso, preferem hoje os autores falar em três dimensões de direitos do homem (E. Ridel) e não de três gerações" (CANOTILHO, 2000, p. 381).
} 
civis (direitos de primeira geração); 2a) Direitos políticos (direitos de segunda geração); 3a) Direitos econômicos e sociais (direitos de terceira geração); ${ }^{4} 4$ a ) Direitos concernentes ao patrimônio genético de cada indivíduo e; 5a) Direitos referentes ao espaço cibernético.

A primeira geração de direitos surgiu, no século 18, com as declarações de direitos de 1776 (Declaração da Virgínia) e de 1789 (Declaração dos Direitos do Homem e do Cidadão). Essa geração pode ser denominada de direitos civis ou liberdades civis clássicas, e está estritamente relacionada com o surgimento do Estado moderno em sua versão liberal. Além de direitos ou liberdades civis clássicas, estes direitos podem ser chamados também de direitos negativos, que são estabelecidos contra o Estado.

Daí, portanto, a afirmação de Norberto Bobbio de que entre eles estão "todos aqueles direitos que tendem a limitar o poder do Estado e a reservar para o indivíduo, ou para os grupos particulares, uma esfera de liberdade em relação ao Estado" (1992, p. 32). Com isso, esses direitos estabelecem um marco divisório entre a esfera pública (Estado) e a esfera privada (sociedade civil). ${ }^{5}$ Essa distinção entre esfera pública e esfera privada é uma das características fundamentais da sociedade moderna, e é a partir dela que se estrutura, em boa medida, o pensamento liberal e o pensamento democrático.

Quais, no entanto, são esses direitos de primeira geração? Entre esses direitos pode-se colocar as liberdades físicas (direito à vida, liberdade de locomoção, direito à segurança individual, direito à inviolabilidade de domicílio, direito de reunião e de associação), as liberdades de expressão (liberdade de imprensa, direito à livre-manifestação do pensamento, direito ao sigilo de correspondência), as liberdades de consciência (liberdade de consciência filosófica, liberdade de consciência política, liberdade de consciência religiosa), o direito de propriedade privada, os direitos da pessoa acusada (direito ao princípio da reserva legal, direito à presunção de inocência, direito ao devido processo legal) e as chamadas garantias dos direitos (direito de petição, direito ao habeas corpus, direito ao mandado de segurança). ${ }^{6}$

A segunda geração de direitos surgiu no decorrer do século 19 e pode ser denominada de direitos políticos ou liberdades políticas. Essa geração de direitos se "processou na esteira das potencialidades democráticas da cidadania civil, ou seja, na esteira dos direitos civis" (PEREIRA DE ANDRADE, 1993, p. 19) e, como tal, não é possível esquecer e pode ser vista como o desdobramento consequente da primeira geração de direitos (direitos civis). ${ }^{7}$

Essa vinculação entre direitos civis e direitos políticos não deve, contudo, impedir a compreensão da especificidade de cada uma dessas gerações de direitos. A primeira geração caracteriza-se pelo fato de os direitos por ela abrangidos serem considerados direitos negativos, ou seja, direitos estabelecidos contra o Estado. A segunda geração, ao contrário, caracteriza-se pelo fato de os direitos compreendidos pela mesma serem vistos como direitos positivos, isto é, direitos de participar da formação da vontade do Estado.

Esse deslocamento - de contra o Estado para participar da formação da vontade do Estado - é importantíssimo, pois revela o surgimento de uma nova perspectiva da liberdade, que deixa de ser pensada exclusivamente de forma negativa, como não impedimento, para ser compreendida de forma positiva, como autonomia, como possibilidade de participação na esfera pública. Por isso, esta geração de direitos representa um momento de transformação do Estado moderno: de sua versão liberal para sua forma democrática. Entre os direitos desta geração, pode-se colocar o direito ao sufrágio universal, o direito de constituir partidos políticos, o direito de plebiscito, o direito de referendo e o direito de iniciativa popular.

A terceira geração de direitos surgiu no início do século 20, notadamente no decorrer de sua segunda década, por influência da Revolução Russa, da Constituição Mexicana de 1917 e da Constituição de Weimar de 1919, e pode ser denominada de direitos econômicos e sociais. Essa terceira geração de direitos compreende

\footnotetext{
${ }^{4}$ T. H. Marshall (1967) classifica os chamados direitos humanos em três gerações (1a - direitos civis, 2a - direitos políticos e $3 \underline{a}-$ direitos econômicos e sociais - gerações clássicas). É importante destacar, contudo, que podem ser acrescentadas a esta classificação ainda duas novas gerações de direitos: a geração dos direitos difusos (direitos sem um sujeito determinado) e a geração dos direitos de solidariedade (direitos no âmbito internacional).

${ }^{5}$ Utilizamos as expressões Estado e sociedade civil, neste texto, no sentido marxiano (BOBBIO, 1982).

${ }^{6}$ Esta classificação, como as demais utilizadas no texto, não pretende ser exaustiva, mas apenas exemplificativa.

7 Por isso, muitos autores veem esses dois grupos de direitos como sendo parte de uma única geração de direitos (LAFER, 1988).
} 


\section{Debate}

os chamados direitos de créditos, ou seja, os direitos que tornam o Estado devedor dos indivíduos no que se refere à obrigação de realizar ações concretas, visando a garantir-lhes um mínimo de bem-estar material e de igualdade de acesso aos bens materiais produzidos pela sociedade.

Esses direitos são, portanto, não direitos estabelecidos contra o Estado ou direitos de participar na formação da vontade do Estado, mas, sim, direitos garantidos por meio do Estado. Por isso, não estamos diante novamente da ampliação do conceito de liberdade, e sim do reconhecimento jurídico-institucional do princípio da igualdade. Em consequência, esta geração de direitos representa não uma herança do liberalismo ou do pensamento democrático, como no caso das duas primeiras gerações de direitos, mas uma contribuição das ideias social-democráticas ou, mesmo, "um legado do socialismo" (LAFER, 1988, p. 127). ${ }^{8}$

Desta forma, é possível perceber que a presente geração de direitos está intimamente relacionada com o Estado moderno em sua fase mais desenvolvida, conformando o que tem sido denominado de Bem-Estar Social (Welfare State) e suas propostas de construção de uma ampla rede de proteção social. Entre os direitos desta geração estão duas ordens de direitos: 1a) os direitos relativos ao homem trabalhador; 2a) os direitos relativos ao homem consumidor de bens e serviços públicos (SILVA, 1998).

Entre os direitos relativos ao homem trabalhador estão o direito à liberdade de trabalho, o direito ao salário mínimo, o direito à jornada de trabalho de oito horas, o direito ao descanso semanal remunerado, o direito a férias anuais, o direito à igualdade de salários para trabalhos iguais, o direito à liberdade sindical e o direito de greve. Entre os direitos relativos ao homem consumidor de bens e serviços públicos estão, por outro lado, o direito à seguridade social, o direito à educação, o direito à habitação e o direito de viver em um ambiente saudável e sustentável (não poluído).

Para Bobbio (1992), a quarta geração de direitos refere-se aos efeitos drásticos da evolução da pesquisa biológica que permite manipulações do patrimônio genético de cada indivíduo. Esta geração sequer poderia ter sido imaginada por ocasião do reconhecimento dos direitos de primeira ou de segunda geração, que se apresentam como exigências da evolução científica e tecnológica trazidas pelo progresso.

Em razão da possibilidade de utilização destrutiva desses avanços da pesquisa genética, a Unesco, lembrando, solenemente, sua conexão com os princípios universais dos direitos humanos, como os princípios democráticos da dignidade, da igualdade e do respeito mútuo entre os homens, promulgou, no ano de 1997, a Declaração Universal sobre o Genoma Humano e os Direitos Humanos. Esta declaração estabelece, em seu artigo 10, que "o genoma humano constitui a base da unidade fundamental de todos os membros da família humana bem como de sua inerente dignidade e diversidade. Num sentido simbólico, é o patrimônio da humanidade" (ORGANIZAÇÃO..., 2018); e reafirma que a todo o indivíduo é devido respeito a sua dignidade e aos seus direitos, independentemente de suas características genéticas, devendo ser respeitado quanto a sua singularidade e diversidade. Também assevera que o genoma humano em seu estado natural não deve ser objeto de transações financeiras.

Por sua vez, outros autores, como Canotilho (2000), Bonavides (1993) e Trindade (2003), entendem que a quarta geração de direitos surgiu no final da primeira metade do século 20, tendo como grande marco o ano de 1948, e pode ser denominada de direitos de solidariedade. Essa geração de direitos compreende os direitos do homem no âmbito internacional, ou seja, os direitos que, "não se destinam especificamente à proteção dos interesses de um indivíduo, de um grupo ou de um determinado Estado. Têm por destinatário o gênero humano mesmo num momento expressivo de sua afirmação como valor supremo em termos de existencialidade concreta" (BONAVIDES, 1993, p. 481). Por isso, não são direitos contra o Estado, direitos de participar do Estado ou direitos por meio do Estado, mas, sim, direitos sobre o Estado. Entre os direitos desta quarta geração estão, também, o direito à autodeterminação dos povos, o direito à paz, o direito ao patrimônio comum da humanidade, o direito ao meio ambiente sadio e o direito ao desenvolvimento.

\footnotetext{
${ }^{8}$ Esta heterogeneidade de origem das duas primeiras gerações de direito em relação a terceira, tem levado alguns pensadores a afirmar que as referidas gerações de direitos são incompatíveis. Ver, neste sentido, HAYEK, Friedrich August Von. Direito, legislação e liberdade. São Paulo: Visão, 1985. 3 v. Discorda-se desses posicionamentos, pois, como nos informa Luciano de Oliveira, "(...) se considerarmos a experiência histórica das democracias européias, não somente não havia incompatibilidade entre esses dois gêneros de direitos, mas, o que é mais importante, haveria mesmo complementaridade - os direitos de créditos sendo, de uma certa maneira, um prolongamento dos direitos-liberdades, na medida em que a dinâmica das sociedades democráticas consiste essencialmente em integrar, progressivamente, os excluídos da liberdade" ([198-?], p. 8).
} 
Como quinta geração de direitos encontram-se os relacionados ao espaço cibernético (ciberespaço realidade virtual): a cibercultura. ${ }^{9} \mathrm{O}$ progresso tecnológico promovido no final do século 20 colocou os indivíduos diante de inumeráveis possibilidades de uma realidade virtual, até então não vivenciada pelas sociedades, da qual praticamente não há controle (as formas tradicionais de controle não se mostram suficientes para essa nova fase do progresso tecnológico). Assim, novas exigências sociais, tecnológica e científicas dão origem a quinta geração de direitos do homem, como decorrência de novos sistemas sociais em que há o deslocamento das relações sociais de contextos locais de interação e sua reestruturação por meio de extensões indefinidas de tempo e espaço (GIDDENS, 1991), por intermédio da internet.

Esta quinta geração de direitos ocupa-se da preocupação com a difusão e o desenvolvimento da cibernética na atualidade. Bustamante (1999), ao comentar a proposta de Declaração de Direitos Humanos no Ciberespaço com fundamento na Declaração Universal dos Direitos Humanos da ONU, alude que este é mais um ambiente para que indivíduos e grupos possam refletir sobre suas próprias políticas e ações na rede global de telecomunicações, com o objetivo de promover neste os ideais humanos e uma ética da solidariedade.

Estas são, em síntese, as gerações de direitos do mundo moderno: direitos civis, direitos políticos, direitos econômicos e sociais, direitos difusos e direitos de solidariedade. As três primeiras gerações são conhecidas como as grandes gerações de direitos (ou as clássicas gerações de direitos). Dessa forma, os primeiros são direitos negativos, os segundos são direitos positivos, e os terceiros são direitos de créditos, devendo ser garantidos pelo Estado. Quanto às gerações mais recentes (quarta e quinta), são direitos de solidariedade, direitos sobre o Estado.

\section{O DIREITO AO ACESSO À JUSTIÇA}

A preocupação com a proteção ao direito de acesso à justiça surgiu com a primeira geração de direitos, apesar de alguns autores encontrarem antecedentes em períodos históricos anteriores (CARNEIRO, 2000; MADERS, 2004). A sua afirmação indica, de maneira ampla, que o sistema de justiça (principalmente o Poder Judiciário) deve ser acessível, de forma igualitária, a todos os cidadãos e que este acesso produza resultados que sejam individual e socialmente justos (CAPPELLETTI; GARTH, 1988).

Em que pese a importância destas duas perspectivas, para efeito deste trabalho o direito de acesso à justiça será entendido predominantemente como o direito de acesso, de forma igualitária, ao sistema de justiça (especialmente ao Poder Judiciário). ${ }^{10}$ Neste sentido específico, o direito de acesso à justiça sofreu, desde o seu surgimento, uma alteração conceitual importante, tendo se transformado de um direito civil (e, portanto, de um direito negativo) em um direito social (e, então, positivo). Esta transformação ocorreu no transcurso da primeira metade do século 20 e se consolidou em suas últimas três ou quatro décadas.

Dominado por Estados liberais, constatava-se que até esse momento histórico os procedimentos adotados para a solução dos litígios refletiam a filosofia essencialmente restritiva dos direitos humanos e uma política de abstenção do Estado das principais esferas da vida social. Por isso,

O direito ao acesso à proteção judicial significava essencialmente o direito formal do indivíduo agravado de propor ou contestar uma ação. A teoria era de que, embora o acesso à justiça fosse um "direito natural", os direitos naturais não necessitavam de uma ação do Estado para sua proteção. Estes direitos eram considerados anteriores ao Estado; sua preservação exigia apenas que o Estado não permitisse que eles fossem infringidos por outros. O Estado, portanto, permanecia passivo, com relação a problema tais como a aptidão de uma pessoa para reconhecer seus direitos e defendê-los adequadamente, na prática (CAPPELLETTI; GARTH, 1988, p. 9).

Desta forma, ficava claro que o direito de acesso à justiça era apenas um direito formal a que poucos tinham acesso, pois o seu exercício dependia, para ser efetivo, como a aquisição de qualquer outro bem no sistema do laissez-faire, de recursos próprios para a cobertura dos custos. Como a maioria das pessoas não

\footnotetext{
${ }_{9}^{9}$ Sobre a cibercultura ver a obra de Pierre Lévy, publicada em 1997, denominada "Cyberculture".

${ }^{10}$ Para além destas duas perspectivas, é possível afirmar que o direito de "acesso à Justiça não pode ser estudado nos acanhados limites do acesso aos órgãos judiciais já existentes. Não se trata apenas de possibilitar o acesso à Justiça enquanto instituição estatal, e sim de viabilizar o acesso à uma ordem jurídica justa" (WATANABE, 1988, p. 128). Em razão dos limites deste trabalho, a análise deste ângulo mais amplo do direito de acesso à justiça também não será aprofundada.
} 


\section{Debate}

dispunha desses recursos, o direito de acesso à justiça adquiriu o caráter de uma garantia abstrata, pois vinha desacompanhado de qualquer instrumento que assegurasse a eficácia da prestação jurisdicional, no sentido de que a este aspecto procedimental se adicionasse, objetivamente, uma "composição igualitária, paritária e equânime, centrada única e tão-somente, no dizer o direito conforme o que melhor o tivesse [...]" (RIBEIRO, 1998, p. 52). Por isso, era apenas um direito formal de ação diante dos poderes públicos.

Esse cenário, com as transformações do final do século 19 (especialmente com a emergência da classe trabalhadora como força política importante) e com a emergência do constitucionalismo social nas primeiras duas décadas do século 20 , foi sendo alterado, tendo o acesso à justiça passado a ser "progressivamente reconhecido como tendo uma importância fundamental entre os novos direitos individuais e sociais, uma vez que a titularidade de direitos é destituída de sentido, na ausência de mecanismos para sua efetiva reivindicação" (CAPPELLETTI; GARTH, 1988, p. 11-12).

Nas palavras de Boaventura de Sousa Santos:

[...] a consagração constitucional dos novos direitos econômicos e sociais e a sua expansão paralela à do Estado de bem-estar transformou o direito ao acesso efetivo à justiça num direito charneira, um direito cuja denegação acarretaria a de todos os demais. Uma vez destituídos de mecanismos que fizessem impor o seu respeito, os novos direitos sociais e econômicos passariam a meras declarações políticas, de conteúdo e função mistificadores. Daí a constatação de que a organização da justiça civil e em particular a tramitação processual não podem ser reduzidas a sua dimensão técnica, socialmente neutra, como era comum serem concebidas pela teoria processualística [liberal] [...] (1989, p. 45-46).

A proteção judicial dos direitos humanos deixou de ser vista, portanto, como uma dimensão apenas técnico-jurídica (direito de ação) para se tornar uma garantia essencial de toda a sociedade democrática e um dos elementos constitutivos do Estado Democrático de Direito. Por isso é que, neste contexto, uma das maiores ameaças aos direitos humanos passou a residir "na incapacidade do Estado em assegurar sua efetiva realização. Essa incapacidade, revelada pela ausência de mecanismos de materialização dos direitos reconhecidos, traduz-se na negação do próprio Estado, constituído como democrático e de direito (ANNONI, 2003, p. 114). Em consequência, o direito de acesso à justiça passou a "ser encarado como o requisito fundamental - o mais básico dos direitos humanos - de um sistema jurídico moderno e igualitário que pretenda garantir, e não apenas proclamar os direitos de todos" (CAPPELLETTI; GARTH, 1988, p. 12).

Com efeito, foi sendo reconhecido cada vez mais que um direito, formalmente declarado, mas que não é assegurado pelo poder público e nem pode ser usufruído pelo seu titular, é, na verdade, um falso direito, uma espécie de insígnia pomposa e inútil. Isto é, passou-se a perceber, cada vez mais, que os direitos

[...] são letra morta na ausência [de instrumentos] e de instâncias que garantem o seu cumprimento. 0 Judiciário, desde este ponto de vista, tem um papel central. Cabe a ele aplicar a lei e, conseqüentemente, garantir a efetivação dos direitos individuais e coletivos. Daí ser legítimo afirmar que o Judiciário é o principal guardião da liberdade e da cidadania (SADEK, 2001, p. 7).

Esta mudança veio acompanhada também da percepção de que o Estado deve ter uma participação positiva na efetivação dos direitos humanos e na distribuição dos bens socialmente produzidos. Em consequência, adquiriu feições cada vez mais sociais e impulsionou, ainda no início dos anos 70 do século 20, um conjunto de reformas destinadas a ampliar a concretização do direito de acesso à justiça. Estas reformas concentraram-se no enfrentamento, como lembram Cappelletti e Garth (1988), das custas judiciais, da diferença entre as partes e da ausência de instrumentos legais de defesa dos direitos coletivos ou direitos difusos.

Em relação às custas judiciais, preocupou-se com o fato de as mesmas serem muito altas, desproporcionais aos valores das causas em questão e inadequadas diante da lentidão do processo judicial. No que se refere à diferença entre as partes, chamou-se a atenção para a desigualdade de recursos financeiros existente entre as partes na busca de seus direitos, na diferença de aptidão para reconhecer e defender estes direitos e na desigualdade de familiaridade com o sistema judicial. Por fim, quanto à ausência de instrumentos legais de defesa dos direitos difusos, destacou-se as dificuldades de ação conjunta e de construção de convergência entre os diversos interessados, pois, "embora as pessoas na coletividade tenham razão bastante para reivindicar um interesse difuso, as barreiras à sua organização podem, ainda assim, evitar que o interesse seja unificado e expresso" (CAPPELLETTI; GARTH, 1988, p. 27). 
Com o objetivo de superar estas dificuldades, emergiram, a partir da década de 60, várias pressões direcionadas à "ampliação dos canais de acesso à justiça, no sentido de se garantir efetivamente os novos direitos que vinham sendo conquistados por determinadas minorias (negros, mulheres) ou pela sociedade (direito do consumidor)" (CAVALCANTI, 1999, p. 32). É neste contexto que surge o Florence Projec, ${ }^{11}$ financiado pela Ford Faundation, que propôs três soluções:

A primeira solução para o acesso à justiça - primeira "onda" deste movimento novo - foi a assistência judiciária; a segunda dizia respeito às reformas tendentes a proporcionar representação jurídica para os "interesses difusos", especialmente nas áreas da proteção ambiental e do consumidor; e o terceiro - e mais recente - é o que nos propomos a chamar simplesmente "enfoque de acesso à justiça" porque inclui os posicionamentos anteriores, mas vai muito além deles, representando, desta forma, uma tentativa de atacar as barreiras ao acesso de modo mais articulado e compreensivo (CAPPELLETTI; GARTH, 1988, p. 31). ${ }^{12}$

A primeira solução ou "onda" consistiu no estabelecimento da garantia de que sejam proporcionados, aos que não possuem recursos econômicos suficientes, serviços jurídicos de forma gratuita, tendo em vista a necessidade de assistência de um advogado para a busca da efetivação de um direito de um ponto de vista judicial. 0 estabelecimento desta garantia pressupõe duas ações concretas: antes do pleito judicial, informação e orientação; durante o pleito judicial, assistência judiciária propriamente dita. Neste sentido, afirma Cappelletti que,

[...] não basta a assistência, através de advogado, em juízo. Pode ocorrer que a assistência extra e pré-judicial seja mais necessária, porque pobreza significa, normalmente, não apenas pobreza econômica, mas, também, pobreza jurídica. Isto é, pobreza de informação. Os pobres não conhecem seus direitos e assim não dispõem de informação suficiente para saber o que podem fazer para se protegerem, para obterem os benefícios que o direito substancial poderia Ihes garantir (1995, p. 48).

Além disso, é necessário perceber que estes serviços, diante da crescente complexidade da sociedade moderna e de seus procedimentos judiciais, tornaram-se essenciais. Neste sentido, "[...] a assistência judiciária àqueles que não podem custear [as despesas de um processo] são, por isso mesmo, vitais" (CAPPELLETTI; GARTH, 1988, p. 32). Preocupados com este fato, os governos de alguns países (como Alemanha e Inglaterra) introduziram, ainda no transcorrer da primeira metade do século 20, algumas reformas voltadas para a construção de mecanismos de assistência judiciária financiados pelo Estado. ${ }^{13}$ Apesar de suas fragilidades, estas primeiras reformas foram fundamentais para o início do movimento para superação dos anacrônicos semicaritativos programas de acesso à justiça, herdados do século 19. Estes instrumentos eram típicos do laissez-faire e do liberalismo então hegemônico e se materializavam em ações principalmente honoríficas dos advogados (CAPPELLETTI; GARTH, 1988).

Estas iniciativas tornaram-se mais intensas a partir das década de 60 e 70 do século 20 . Neste sentido, novas experiências foram sendo construídas, como, por exemplo, nos Estados Unidos (Office of Economic Opportunity), na França (Securité Sociale), na Suécia (Public Legal Aid Law) e na Inglaterra (Legal Advice and Assistence Act).$^{14}$ Estas iniciativas foram posteriormente aperfeiçoadas, tendo impulsionado a criação do chamado Sistema Judicare,$^{15}$ o Sistema do Advogado Remunerado pelo Estado ${ }^{16}$ e, até mesmo, a modelos combinados (CAPPELLETTI; GARTH, 1988).

\footnotetext{
${ }_{11}$ Projeto de Pesquisa sobre o acesso à justiça coordenado por Mauro Cappelletti e Bryant Garth e que foi concluído em 1978. Participaram do projeto pesquisadores de várias áreas e juristas de inúmeros países (Estados Unidos, Inglaterra, França, Alemanha, etc.). O resultado do trabalho foi publicado pelos coordenadores sob o título Acesso à Justiça (1988). O Brasil, infelizmente, não participou deste projeto, estando a América Latina representada por México, Chile, Colômbia e Uruguai (CAVALCANTI, 1999).

${ }^{12}$ Outras formas de classificar os principais problemas do acesso à justiça e as respectivas soluções sugeridas podem ser encontradas. Entre estas, pode ser vista a classificação realizada por José Cichocki Neto na obra Limitações ao acesso à Justiça (1999).

${ }^{13}$ No Brasil isso ocorreu por meio da Lei Federal no 1.060 de 1950, que estabeleceu as normas para concessão de assistência judiciária gratuita aos necessitados. Hoje, sobre o tema vigoram os artigos 98 a 102 do novo Código de Processo Civil, instituído pela Lei Federal no 13.105 de 2015.

${ }^{14}$ Outros exemplos podem ser encontrados na obra de Mauro Cappelletti e Bryant Garth (1988).

${ }^{15}$ Trata-se de um sistema pelo qual a assistência judiciária é estabelecida como um direito para todas as pessoas que se enquadram nos termos da lei. Neste sistema os advogados são pagos pelo Estado. A finalidade do sistema judicare é proporcionar aos litigantes de baixa renda a mesma representação que teriam se pudessem pagar um advogado (CAPPELLETTI; GARTH, 1988).

${ }^{16}$ Sistema inspirado pelo Programa de Serviços Jurídicos do Office Of Economic Opportuny dos Estados Unidos, que tem por finalidade não apenas prestar assistência jurídica aos necessitados, mas torná-los conscientes de seus direitos e desejosos de utilizar advogados para ajudar a obtê-los (CAPPELLETTI; GARTH, 1988).
} 


\section{Debate}

Estas reformas, principalmente quando vistas em conjunto, foram fundamentais para a ampliação do acesso à justiça. Em consequência de sua institucionalização, as barreiras do acesso à justiça começam a ceder em vários países do ocidente. Por isso, afirmam Cappelletti e Garth (1988) que os pobres, "obtendo assistência judiciária em números cada vez maiores, não apenas para causas de família ou defesa criminal, mas também para reivindicar seus direitos novos, não tradicionais, seja como autores ou como réu" (p. 47). Neste sentido, esta "onda" ou solução para o acesso à justiça revelou-se um instrumento de inclusão social extremamente importante.

A segunda "onda" ou solução consistiu no esforço de melhorar o acesso à justiça mediante a criação de mecanismos jurídicos que possibilitem a representação dos interesses difusos, assim chamado os interesses coletivos ou grupais, diversos daqueles dos pobres. Para tanto, foi necessário enfrentar a concepção de que o processo civil deveria apenas constituir-se "um assunto entre duas partes, que se destinava à solução de uma controvérsia entre essas mesmas partes a respeito de seus próprios interesses individuais" (CAVALCANTI, 1999, p. 35). Isto significa que "a concepção tradicional de processo civil não deixava espaço para a proteção dos direitos difusos" (CAPPELLETTI; GARTH, 1988, p. 49) e que era necessário a superação desta visão individualista do processo judicial, permitindo o surgimento de novos instrumentos jurídicos e novos procedimentos judiciais que permitissem a representação dos interesses coletivos.

Neste sentido, foi reforçada a Ação Governamental, incluindo a criação de agências públicas regulamentadoras altamente especializadas, o Advogado Público (Estados Unidos) e o Ombudsman do Consumidor (Suécia), a Técnica do Procurador-Geral Privado e a Técnica do Advogado Particular de Interesse Público, incluindo a possibilidade de proposição de ações coletivas (CAPPELLETTI; GARTH, 1988). Todas as iniciativas, como se pode ver, são extremamente relevantes e possuem como objetivo superar a "pobreza organizativa" dos diversos grupos humanos (CAPPELLETTI, [199-?]) e dar "maior eficácia, quanto à celeridade e efetividade da prestação jurisdicional, para o atendimento de pretensões coletivas [pelo Poder Judiciário]" (RIBEIRO, 1998, p. 57).

A terceira "onda" ou solução consistiu em buscar instrumentos que superem os obstáculos propriamente processuais do acesso à justiça. Isto quer dizer que esta terceira "onda" volta-se para aspectos que podem ser definidos como infrassistêmicos, "cuja ênfase recai sobre fórmulas para a simplificação dos procedimentos da justiça estatal e/ou criação de formas extrajudiciais de resolução dos conflitos" (CAVALCANTI, 1999, p. 35). Deste modo, temos, além da simplificação processual e substancial, também, como lembra Cappelletti, o recurso

[...] as formas quase-judiciárias ou não-judiciárias [de acesso à justiça]. Exemplo: controvérsias entre vizinhos, entre familiares. A utilização de formas de conciliação e de mediação tem sido muito importante como instrumento para a simplificação e resolução dos litígios. Essencialmente, a idéia básica é a tentativa de desburocratização, desformalização. Alguns falam até em deslegalização, como tentativa de resolver essa tendência à burocracia, à lentidão judiciária (1995, p. 52).

Dito de outra maneira, esta terceira "onda" de reformas de acesso à justiça representa a preocupação com o esgotamento da capacidade de resposta do Poder Judiciário diante do crescente aumento de direitos reconhecidos, da litigiosidade das sociedades atuais e da universalização da jurisdição. Além disso, não é possível desconhecer também que esta solução se fortalece diante da atual crise regulatória do direito e da crescente fragilidade da esfera político-estatal.

Por isso, esta terceira forma de solução ou "onda" de acesso à justiça "tem representado uma importante, talvez a mais importante, expressão de uma radical transformação do pensamento jurídico e das reformas normativas e institucionais em um número crescente de países" (CAOVILLA, 2003, p. 33). Em consequência, é importante destacar que ela vem acompanhada de grandes desafios, em especial do risco de que procedimentos menos formalizados - e, portanto, mais eficientes e, na maioria dos casos, mais baratos - abandonem as garantias fundamentais do processo. Este risco não pode, como lembram Cappelletti e Garth (1988), ser esquecido.

Estas são, portanto, as três grandes soluções ou "ondas" apresentada pelo Florence Project para um maior acesso à justiça. A primeira "onda" preocupou-se com a assistência judiciária aos pobres; a segunda "onda" voltou-se à criação de instrumentos jurídicos e procedimentos judiciais aptos à proteção dos direitos difusos; a terceira "onda" direcionou-se para a simplificação dos procedimentos judiciais e a criação de mecanismos alternativos de justiça. 
Neste sentido, é possível concluir que o direito de acesso à justiça teve, durante o mundo moderno, uma expansão significativa: 10) firmou-se, num primeiro momento, como um direito civil (com a característica de ser um direito formal de ação ou de ingresso em juízo para a defesa de um direito); 29) transformou-se, a seguir, em direito social (fundamental para a garantia dos demais direitos); 3 ?) transformou-se, num terceiro momento, de um direito individual em um direito coletivo (com a proteção dos interesses difusos); 4으) tornou-se, por fim, um direito que, além da garantia do acesso ao Poder Judiciário, abrange o acesso à procedimentos jurídicos simplificados ou, até mesmo, a formas extrajudiciais de solução dos conflitos. ${ }^{17}$

\section{A PROTEÇÃO NACIONAL E INTERNACIONAL DO DIREITO DE ACESSO À JUSTIÇA}

As soluções propostas pelo Florence Project foram adotadas, com suas evidentes especificidades, em praticamente todos os países ocidentais. Isto não foi muito diferente no Brasil. Não é possível afirmar, contudo, que no Brasil o direito de acesso à justiça teve a mesma trajetória histórica. Ao contrário, até o início dos anos 80 do século 20 este direito, como todos os demais direitos humanos, tinha uma enumeração muito formal, pois o processo de consolidação da democracia é bastante recente no Brasil e, em consequência, a preocupação com os direitos humanos.

O que se procura esclarecer é que, apesar de declarado desde a Constituição de 1946 (artigo 141, §4)), este direito tornou-se mais efetivo com a promulgação da Constituição de 1988 e com as práticas políticas e jurídicas que the deram forma e que se consolidaram a partir de sua experiência. Isto também não significa que se desconhece a importância e a relevância da Lei 1.060, de 1950, que tratou de normatizar a concessão da assistência judiciária gratuita aos necessitados, regulamentado o disposto na Constituição de $1946 . \mathrm{Na}-$ quela época, contudo, o acesso à justiça, por meio da assistência judiciária gratuita, não era compreendido da mesma forma como o é na atualidade. O que se quer afirmar é que os direitos e garantias fundamentais foram, em razão da especificidade da formação do país ao longo de sua história, inacessíveis à grande maioria da população.

A Constituição de 1988, como um marco fundamental de um momento histórico de democratização do Brasil, tenta romper com esta tradição. Neste sentido, além de declarar, já a partir de seu artigo 5o, o conjunto mais amplo de direitos e garantias fundamentais de toda a trajetória constitucional brasileira, preocupa-se também em universalizar o acesso à jurisdição (artigo 50, XXXV) e a proteger não apenas os direitos individuais, mas também os direitos coletivos e os direitos sociais.

Neste sentido, é possível observar que a atual Constituição brasileira optou pelo Estado Democrático de Direito e, portanto, pelas exigências sociais de tutela dos novos direitos. Por isso, afirma-se que a proteção ao direito de acesso à justiça previsto é bastante abrangente, incluindo a elevação de inúmeros princípios processuais a direitos constitucionais. Isto deixa claro que a Constituição de 1988 fez uma opção política-institucional pela ampliação do direito de acesso à justiça. Desta forma, constitucionalizou a garantia do

[...] princípio do devido processo legal (Art, 5ㅇ, inc. LIV); o contraditório e a ampla defesa (inc. LV); o Juiz natural (inc. LIII); a assistência jurídica integral e gratuita aos que necessitarem da tutela jurisdicional (inc. LXXIV); e os instrumentos processuais constitucionais do mandado de segurança, individual e coletivo, do habeas corpus, do habeas data, o mandado de injunção, a ação popular, além de outros direitos e garantias acolhidos por tratados internacionais de que o Brasil faz parte (CICHOCKI NETO, 2001, p. 95).

Por outro lado, é importante observar que foi a partir da década de 80 que surgiram, reforçados, posteriormente, pela Constituição de 1988, os principais diplomas legais que, de alguma forma, buscam facilitar o acesso à justiça e simplificar alguns de seus procedimentos. Assim,

[...] a Lei 7.019/82 que criava o procedimento de arrolamento de bens em caso de partilha amigável; a Lei $7.224 / 84$, instituindo o Juizado de Pequenas Causas, atualmente substituído pelos Juizados Especiais Cíveis e Criminais, regulamentados pela Lei 9.099/95; a Lei 7.347/85 disciplinando a ação civil pública; a Lei 9.079/95,

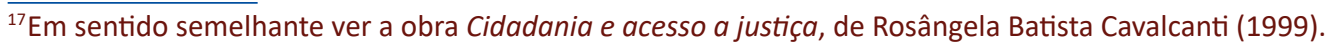


que disciplinou o procedimento monitório; as reformas de 94 e 95 ao Código de Processo Civil e as recentes Leis 10.352/2001 e 10.358/2001 que ampliaram as Reformas anteriores, especialmente quanto ao sistema recursal (LIMA FILHO, 2003, p. 140).

Todas as leis, como se podem observar, foram criadas com o objetivo de ampliar o direito de acesso à justiça. Por isso, é possível perceber que o Brasil já incorporou, em boa medida, as sugestões feitas pelo Florence Project. Com efeito, registra-se que possui legislação prevendo a concessão da assistência judiciária aos que precisam, tem mecanismo de proteção aos direitos difusos ou coletivos e está simplificando os seus procedimentos judiciais e adotando novas formas de solução dos conflitos.

Recentemente entrou em vigor o Novo Código de Processo Civil, Lei 13.105/2015, que revogou alguns dispositivos da antiga Lei 1.060/50, mas trouxe para dentro do próprio Código de Processo Civil a disciplina da Gratuidade da Justiça anteriormente denominada "assistência judiciária". A gratuidade da justiça, prevista nos artigos 98 ao 102 do referido Código, é dirigida tanto à pessoa natural quanto à pessoa jurídica, brasileira ou estrangeira. O pressuposto para a concessão do benefício da gratuidade, todavia, é a insuficiência de recursos da parte de arcar com as despesas processuais. Tratando-se de pessoa natural, presume-se verdadeira a simples alegação de insuficiência de recursos junto aos autos do processo, e é ideal que o faça na primeira oportunidade em que manifestar-se nos autos. Em relação à pessoa jurídica, o juiz poderá exigir a comprovação da alegada insuficiência (REDONDO, 2016). De um modo geral, a matéria a respeito da gratuidade da justiça parece ter sido engessada pela nova lei, na medida em que se preocupa de forma demasiada em que esse benefício da gratuidade aconteça somente em casos extremos. Se assim for, significa um retrocesso diante da importância da contribuição do resultado de projetos de pesquisa de direito comparado e da produção intelectual internacional para a criação de instrumentos que ampliem o acesso à justiça no Brasil.

Por outro lado, é importante observar que o direito de acesso à justiça também é uma preocupação da legislação internacional. Com efeito, pode-se lembrar que o artigo $X$ da Declaração Universal dos Direitos do Homem, proclamada em 10 de dezembro de 1948 pela Organização das Nações Unidas, afirma que "toda a pessoa tem direito, em condições de plena igualdade, de ser ouvida publicamente e com eqüidade, por um tribunal independente e imparcial, para a determinação de seus direitos e obrigações, ou para o exame de qualquer acusação contra ela dirigida, em matéria penal." ${ }^{\prime 18}$

Da mesma forma, o Pacto internacional de Direitos Civis e Políticos, de 16 de dezembro de 1966, no seu artigo 14, 1, prescreve:

[...] todas as pessoas são iguais perante os tribunais. Toda a pessoa terá direito a ser ouvida publicamente e com as devidas garantias por um tribunal competente, independente e imparcial, instituído por lei, no tocante a qualquer acusação de caráter penal contra ela formulada ou para a determinação de seus direitos e obrigações de caráter civil. ${ }^{19}$

A mesma proteção pode ser encontrada em Convenções de Direitos Humanos Regionais. A Convenção Europeia para a Proteção dos Direitos do Homem e das Liberdades Fundamentais, de 4 de novembro de 1950, por exemplo, estabelece, em seu artigo 60, 1, que "toda a pessoa tem direito a que sua causa seja examinada eqüitativa e publicamente num prazo razoável, por um tribunal independente e imparcial instituído por lei, que decidirá sobre os seus direitos e obrigações civis ou sobre o fundamento de qualquer acusação em matéria penal dirigida contra ela." ${ }^{20}$

No mesmo sentido, a Convenção Americana sobre Direitos Humanos, de 22 de novembro de 1969, prescreve, em seu artigo 8ㅇ, 1, que:

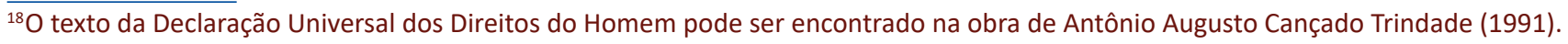

${ }^{19} \mathrm{O}$ texto do Pacto Internacional de Direitos Civis e Políticos poder ser encontrado na obra de Antônio Augusto Cançado Trindade (1991).

${ }^{20} \mathrm{O}$ texto da Convenção Européia para a Proteção dos Direitos do Homem e das Liberdades Fundamentais pode ser encontrado na obra de Antônio Augusto Cançado Trindade (1991).
} 
[...] toda a pessoa tem direito a ser ouvida com as devidas garantias e dentro de um prazo razoável por um juiz ou tribunal competente, independente e imparcial, estabelecido por lei anterior, na defesa de qualquer acusação penal contra ela formulada, ou para a determinação de seus direitos e obrigações de ordem civil, trabalhista, fiscal ou de qualquer outra natureza. ${ }^{21}$

Assim, percebe-se claramente que a legislação internacional tem também a preocupação de garantir a proteção do direito de acesso à justiça. Apesar de não entrar em detalhe, como ocorre com as ordens jurídicas internas, as organizações internacionais são unânimes em reconhecer o direito de acesso à justiça como um dos mais importantes direitos humanos. Na verdade, percebe-se que este direito é um dos instrumentos vitais das sociedades democráticas.

Por isso, nos países em que este direito não for respeitado todo o sistema de direitos e garantias fundamentais não poderá ser sustentado, pois onde o direito de acesso à justiça não for respeitado não há como assegurar o funcionamento do sistema democrático e nem estabelecer o controle do poder, tampouco apurar as eventuais ilegalidades praticadas pelo Estado. Neste sentido, o direito de acesso à justiça constitui-se numa garantia fundamental dos demais direitos e o alicerce da democracia moderna.

\section{CONSIDERAÇÕES FINAIS}

Compreendido este papel do direito de acesso à justiça enquanto direito humano, é importante destacar, mais uma vez, para finalizar, que este direito envolve não apenas os aspectos técnicos de uma reparação ou de proteção diante de uma acusação feita, por exemplo, pelo Estado. Com efeito, o direito de acesso à justiça, quando não observado, coloca em questão o próprio sentido do viver em sociedade. É que a jurisdição - e seu exercício com equidade - constitui-se uma das formas de concretização do próprio Estado, que tem no acesso à justiça uma forma de mediação democrática dos conflitos.

O direito de acesso à justiça é, neste sentido, um direito que reflete uma maneira específica da convivência humana (viver em sociedade), voltada para a tolerância mútua e para a solução dos conflitos por meio do direito. Por isso, o direito de acesso à justiça constitui-se num instrumento de pacificação social e de educação para a convivência coletiva. Em outras palavras, é um instrumento que possibilita a concretização de um Estado de justiça social fundado na igual proteção jurídica de todos e no respeito à dignidade da pessoa humana.

\section{REFERÊNCIAS}

ANNONI, Danielle. Direitos humanos e acesso à justiça no direito internacional: responsabilidade internacional do Estado. Curitiba: Juruá, 2003.

BEDIN, Gilmar Antonio. Os direitos do homem e o neoliberalismo. 3. ed. ljuí: Ed. Unijuí, 2002.

BOBBIO, Norberto. A era dos direitos. Rio de Janeiro: Campus, 1992.

. O conceito de sociedade civil. Rio de Janeiro: Graal, 1982.

BONAVIDES, Paulo. Curso de direito constitucional. São Paulo: Malheiros, 1993.

BUSTAMANTE, Javier. Derechos humanos en el ciberespacio. In: Derechos Humanos: La Condición Humana en La Sociedad Tecnológica. Coord. Graciano González R. Arnaiz Madrid: Tecnos, 1999.

CANOTILHO, J. J. Gomes. Direito constitucional e teoria da constituição. 4. ed. Coimbra: Almedina, 2000.

CAOVILLA, Maria Aparecida. Acesso à justiça e cidadania. Chapecó: Argos, 2003.

CAPPELLETTI, Mauro. Acesso à justiça. In: Revista do Ministério Público. Porto Alegre: Revista dos Tribunais, 1995.

. O acesso à justiça e a função do jurista em nossa época. In: Revista de Processo, São Paulo: Revista dos Tribunais, n. 61, 199[?].

CAPPELLETTI, Mauro; GARTH, Bryant. Acesso à justiça. Tradução Ellen Gracie Northfleet. Porto Alegre: Fabris, 1988.

CARNEIRO, Paulo Cezar Pinheiro. Acesso à justiça: juizados especiais cíveis e ação civil pública. Rio de Janeiro: Forense, 2000. CICHOCKI NETO, José. Limitações ao acesso à Justiça. Curitiba: Juruá, 1999.

CUNHA, Rosanne Gay. O direito fundamental do acesso à justiça. In: Revista Direito e Democracia. Canoas: Ed. Ulbra, 2000.

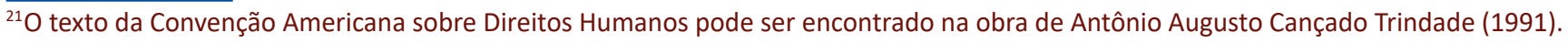


GIDDENS, Anthony. As consequências da modernidade. São Paulo: Ed. Unesp, 1991.

LAFER, Celso. A reconstrução dos direitos humanos. São Paulo: Companhia das Letras, 1988.

LEFORT, Claude. Pensando o político. Rio de Janeiro: Paz e Terra, 1991.

LIMA FILHO, Francisco das Chagas. Acesso à justiça e os mecanismos extrajudiciais de solução de conflitos. Porto Alegre: Sergio Antonio Fabris, 2003.

MADERS, Angelita Maria. O Estado de direito e o acesso à justiça no Brasil. 2004. Dissertação (Mestrado) - Unijuí, curso de Desenvolvimento, Gestão e Cidadania, ljuí, 2004.

MARSHALL. T. H. Cidadania, classe social e status. Rio de Janeiro: Zahar Editores, 1967.

OLIVEIRA, Luciano de. Os direitos humanos como uma síntese da igualdade e da liberdade: ensaio para superar alguns impasses. [198-?]. Mimeo.

ORGANIZAÇÃO DAS NAÇÕES UNIDAS PARA A EDUCAÇÃO, CIÊNCIA E CULTURA (Unesco). Declaração universal sobre o genoma humano e os direitos humanos. Disponível em: <http://unesdoc.unesco.org/images/0012/001229/122990por.pdf>. Acesso em: 18 maio 2018.

PEREIRA DE ANDRADE, Vera Regina. Cidadania: do direito aos direitos humanos. São Paulo: Acadêmica, 1993.

REDONDO, Bruno G. Gratuidade da justiça. In: WAMBIER, Luiz Rodrigues; WAMBIER Teresa Arruda Alvim (Coord.). Temas essenciais do novo CPC: análise das principais alterações do sistema processual civil brasileiro. São Paulo: Revista dos Tribunais, 2016.

RIBEIRO, Antonio Campos. Do acesso à justiça: enfoque brasileiro. In: Revista Científica e Cultural Methodus, Rio de Janeiro: Universidade Estácio de Sá, n. 1, 1998.

SADEK, Maria Tereza (Org.). Acesso à justiça. São Paulo: Fundação Konrad Adenauer, 2001.

SANTOS, Boaventura de Sousa. Introdução à sociologia da administração da justiça. In: FARIA, José Eduardo (Org.). Direito e justiça: a função social do Judiciário. São Paulo: Ática, 1989.

SILVA, José Afonso da. Curso de direito constitucional. 15. ed. São Paulo: Malheiros, 1998.

TRINDADE, Antônio Augusto Cançado. Tratado de direito internacional dos direitos humanos. Porto Alegre: Sergio Antonio Fabris Editor, 2003. V. 1.

WATANABE, Kazuo. Acesso à justiça e sociedade moderna. In: GRINOVER, Ada Pellegrini et al. (Coord.). Participação e processo. São Paulo: Revista dos Tribunais, 1988. 